\title{
A Trajetória da Artificialidade Aplicada ao FoodDesign: Um estudo sobre os episódios da série Chef's Table
}

\author{
The Trajectory of Artificiality Applied to FoodDesign: A study on episodes of Chef's \\ Tables' series
}

CHIARADIA, Bruna; Mestranda em Design; Universidade do Vale do Rio dos Sinos - UNISINOS arqbrunachiaradia@gmail.com

COSTA, Filipe Campelo Xavier da; Doutor em Administração; Universidade do Vale do Rio dos Sinos - UNISINOS

fcampelo@unisinos.br

\begin{abstract}
Resumo
O presente trabalho busca compreender como a trajetória da artificialidade de Krippendorff (2006) pode ser aplicada ao Food Design. A partir das narrativas encontradas nos seis episódios da primeira temporada de Chef's Table, série documental produzida pela Netflix que acompanha seis chefs conhecidos internacionalmente, delineamos os tipos de artefatos citados por Krippendorff (2006) no processo de preparação de pratos da alta gastronomia, da produção do ingrediente ao consumo do alimento.
\end{abstract}

Palavras Chave: trajetória da artificialidade; Chef's Table; food design e gastronomia.

\section{Abstract}

The present paper seeks to understand how the trajectory of the artificiality of Krippendorff (2006) can be applied to Food Design. From the narratives found in the six episodes of the first season of Chef's Table, a documentary series produced by Netflix that accompanies six internationally known chefs, we outline the types of artifacts cited by Krippendorff (2006) in the process of preparing highgastronomy dishes, consumption of food.

Keywords: trajectory of artificiality; Chef's Table; food design and gastronomy.

\section{Introdução}

Para Manzini (2016), os gatilhos que aceleram o processo de reinvenção do design chegam com a virada do século XXI, são eles: a finitude dos recursos naturais do planeta e a globalização através do mundo conectado; impactando sobre a maneira como o ser humano percebe o planeta e como a sociedade se relaciona. A partir desses gatilhos, o design emergente definido por Manzini (2016), começa a tomar forma num processo transitório entre o design tradicional, nascido na cultura industrial dos primórdios do século XX, orientado para o produto, para um design orientado para as questões sociais e ambientais, onde o designer assume papel de articulador dos stakeholders trabalhando de forma transdisciplinar, projetando produtos e serviços de forma integrada com intuito de gerar inovação de maneira sustentável (MANZINI, 2016; MERONI, 2009). 
Em virtude desse processo de reinvenção e da nova maneira com que o designer percebe e atua sobre o mundo, o design enfrenta desafios desconhecidos (KRIPPENDORFF; 2006). Sendo assim, o autor traça a trajetória da artificialidade, construindo e articulando novos precedentes e adicionando novos critérios ao problema de projeto de design. A trajetória descreve de forma progressiva estágios que devem receber a atenção do designer na construção e resolução do problema de projeto, inicia com o produto material e continua por cinco novos níveis de artefatos: bens serviços e identidades, interfaces, redes de usuários e conectividade, projetos e discursos.

Ao mesmo tempo em que o Design se reinventa para compreender e atender a sociedade contemporânea, disciplinas que derivam do Design como, por exemplo, o Food Design, seguem a mesma lógica de evolução. A partir do momento em que é constatado que a maioria dos produtos e serviços alimentícios eram incapazes de atingir os aspectos importantes dos estilos de vida atuais, o Food Design inicia seu processo de transição de uma disciplina atuante apenas no problema estético do alimento ou das ferramentas usadas para a sua preparação, para uma disciplina responsável pela identidade geral do produto e dos serviços alimentícios gastronômicos (FICHLER, 1990 apud: MERONI, 2006). Segundo Francesca Zampollo (2016), atualmente uma das principais pesquisadoras sobre o tema, o Food Design é definido pelo processo projetual que impulsiona a inovação de produtos, serviços ou sistemas de alimentação e o consumo da comida, da produção ao consumo, passando pelo transporte, compra de ingredientes, armazenamento, preservação, preparação, apresentação, etc.

O Food Design é uma disciplina vasta, que engloba uma quantidade de conhecimento quase imensurável. Para dar conta da gama de conhecimentos necessários para desenvolver um projeto de Food Design, Zampollo (2016) o divide em subdisciplinas: Food Product Design (produtos comestíveis concebidos para a produção em massa), Design For Food (produtos não comestíveis que auxiliam no preparo, transporte, servir), Design With Food (alimentos para consumo imediato), Food Space Design (referente ao espaço físico onde se consome o alimento), Eating-Design (situações alimentares únicas), Food Service Design (design de serviços gastronômicos), Food System Design (design de sistemas gastronômicos), Critical Food Design, e Sustainable Food Design (os dois últimos dizem respeito à atitude reflexiva e sustentável do food designer, respectivamente). A partir dessa divisão é possível captar a proporção da transdisciplinaridade do Food Design, cada subdisciplina precisa de profissionais específicos para desenvolvê-las: chefs, técnicos, cientistas, engenheiros, arquitetos, designers, agrônomos, etc. Portanto, este trabalho busca compreender a trajetória da artificialidade da gastronomia, desde a produção do ingrediente até o consumo.

A escolha da série Chef's Table para a aplicação da teoria intercorreu a partir do formato da produção, que de forma documental apresenta na primeira temporada a narrativa de seis chefes consagrados mundialmente por serem inovadores no ramo da alta gastronomia. A série retrata além do processo de preparação do alimento, é apresentado ao espectador o percurso de vida do chef, desde sua formação, experiências, como e porque colecionam estrelas Michelin. Ademais, apresenta todo o processo envolvido na definição do menu, desde cultura e escolha dos ingredientes, os testes e experimentações, a ciência dentro da cozinha, a apresentação do prato, até a forma de atendimento ao cliente.

O desenvolvimento da aplicação acontecerá num primeiro momento com a exposição da teoria da Trajetória da Artificialidade de Krippendorff (2006) em profundidade. Num segundo momento, através de um quadro se dará o cruzamento entre os tipos de artefatos definidos pelo autor, com os episódios da série Chef's Table, delineando a trajetória da artificialidade no processo 
de criação de cada chef, para que por fim sejam localizados os pontos convergência ou divergência das trajetórias, ensaiando a aplicação da trajetória da artificialidade na concepção de um projeto de Food Design.

\section{Trajetória da Artificialidade}

Krippendorff (2006) fundamenta a importância da adição de novos critérios ao projeto de design contemporâneo, através de um panorama da cultura do design que parte da revolução industrial, onde o papel do design era atender a produção em massa, transitando por escolas, que tentam humanizar a cultura de massa elevando o valor estético do produto, ainda que reafirmassem o ditado: "a forma segue a função". A significação dessa expressão para o design, indica que a forma dos produtos revela-se naturalmente a partir da compreensão da função que lhes é designada, e aponta a subordinação do designer à indústria, atendendo especificações vindas de cima como se fossem garantias de sucesso.

No entanto, para sociedade contemporânea, mais complexa e imaterial, o ditado se tornou inepto. O designer assume outras atribuições, e se depara com desafios inexplorados até o momento. O problema de projeto se estende além do produto material, o designer deve estar apto a projetar serviços, plataformas, interfaces, experiências, comunicação e identidades que se apropriam de um discurso específico (KRIPPENDORFF, 2006).

Figura 01: Trajetória da Artificialidade.

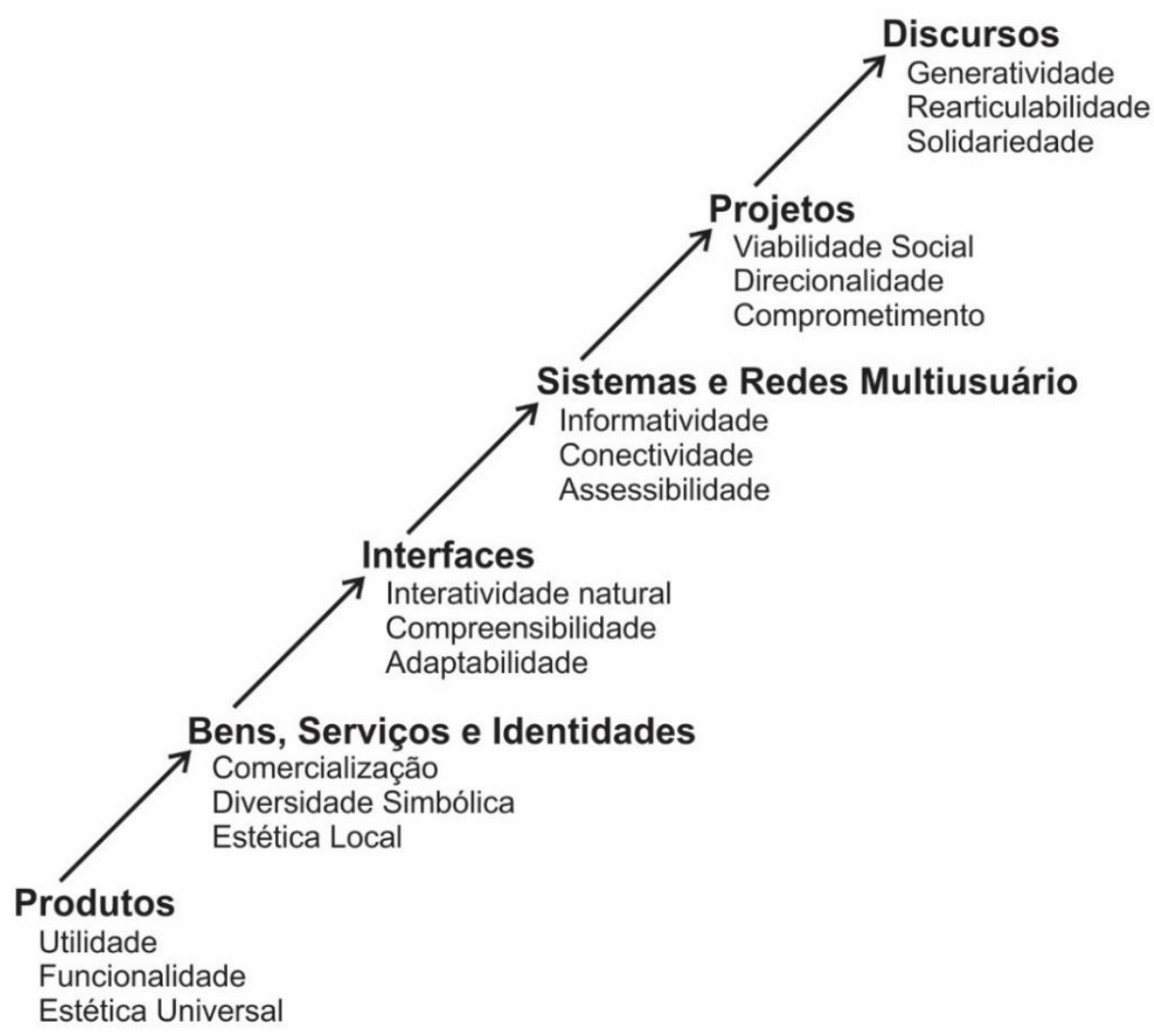

Fonte: tradução de Krippendorf, 2006. 
A partir disso, Klaus Krippendorff (2006), elabora a trajetória da artificialidade, que começa com o produto material, e de forma progressiva transite por cinco "novos tipos de artefatos". Mesmo que apresentados de forma linear pelo autor, Figura 01, a trajetória não se caracteriza como uma ilustração de etapas projetuais irreversíveis, mas como aspectos projetuais que se expandem para os outros níveis de artefatos, construindo e rearticulando os tipos precedentes e adicionando novos critérios de projeto ao design.

O produto é material, tangível, resultado de um processo de fabricação que precisa ser utilitário e funcional. Isso quer dizer que além de atender as demandas utilitárias, o designer deve adotar como critério de projeto o uso "correto" designado pelos produtores, antecipando possíveis usos incompetentes ou não intencionais do produto. Além disso, Krippendorff (2016) afirma que o produto material, atende a uma estética universal, que surge pelo discurso dos designers para justificar uma estética agradável dos produtos em massa, livre de uma cultura única e válida para todos; se propagando do ocidente industrializado para outras culturas subdesenvolvidas, necessitadas de desenvolvimento industrial.

Bens, serviços e identidades, tornaram-se novos tipos de artefatos na década de quarenta, atribuídos de qualidade intangível. Esses tipos de artefatos são projetados a partir da sua capacidade de comercialização. Desta forma, ao projetar bens, serviços ou identidades, o designer tem como objetivo chamar a atenção de grupos de consumidores específicos, portanto, deve estar atento aos hábitos, contexto sociocultural e objetivos de vida dos grupos em questão. Sendo assim, o design de bens, serviços e identidades, deve atender à uma estética local, e levar em consideração as diversidades simbólicas das comunidades (KRIPPENDORFF, 2006).

As interfaces são definidas pelo autor (KRIPPENDORFF, 2006) como o artefato que permite a interação entre homem-máquina. As principais características das interfaces são: a interatividade, a dinâmica e a autonomia. Ademais, devem ser compreensíveis, permitindo que os usuários interajam com a tecnologia de forma natural e com facilidade (usabilidade), e devem ter propriedades de configuração e reconfiguração, atendendo e antecipando as necessidades do usuário, sendo adaptáveis mesmo durante o uso, dispensando a necessidade de habilidades de programação.

Os sistemas e redes multiusuários permitem a organização e coordenação de muitas atividades humanas no espaço e no tempo, a exemplo dos sistemas de sinalização, informação, redes de comunicação, ou das redes de mídia. 0 design de sistemas multiusuários deve levar em conta o contexto e as diversidades culturais que abrangem, além do mais, é quase impossível determinar como um sistema será usado, mas é possível projetá-lo como facilitador para a organização dos seus usuários dentro e ao redor dele (KRIPPENDORFF, 2006).

Os projetos são artefatos provenientes de desejos de mudança, ruptura ou inovação, muitas vezes ligados às áreas de pesquisa e desenvolvimento das companhias. Esses projetos acontecem de forma colaborativa e dialógica entre os participantes (stakeholders). O designer de projetos é designado a ser o articulador e facilitador do grupo de participantes envolvidos, compreendendo em profundidade os objetivos do projeto e comunicando-os aos stakeholders, com intuito de engajá-los no processo projetual (KRIPPENDORFF, 2006).

Por fim, o autor define os discursos como formas organizadas de falar, escrever e atuar de acordo, que por vezes são apoiados por sistemas de multiusuários. Os discursos projetados pelo designer, devem ser generativos, significa que estão abertos a novos vocabulários e metáforas, ao 
mesmo tempo que devem ser solidários, respeitando hábitos, tradições e convenções da comunidade em que se inserem.

\section{Trajetória da Artificialidade x Chef's Table}

Conforme citado na introdução deste artigo, a aplicação da trajetória da artificialidade ao Food Design, é elaborada a partir do estudo do percurso de seis chefs, retratados na primeira temporada da série Chef's Table, produzida pela Netflix. A série documental apresenta a história desses profissionais da gastronomia através das suas práticas cotidianas.

Até aqui, foi possível perceber que a trajetória da artificialidade de Krippendorff (2006), é uma crítica aos paradigmas da era da industrialização aplicados a sociedade contemporânea, para descrevê-la, o autor traz basicamente a relação homem x máquina. Ao propor aplicar esta trajetória para seis diferentes problemas de projeto, onde a relação existente é homem $x$ alimento, surge o desafio de reinterpretar as consoantes orientadas ao design de produto, transpondo-as para as práticas do Food Design e suas subdisciplinas (ZAMPOLLO, 2016), reformulando as definições e significados de cada tipo de artefato, como representado na Figura 02.

Figura 02: Trajetória da Artificialidade Aplicada ao Food Design.

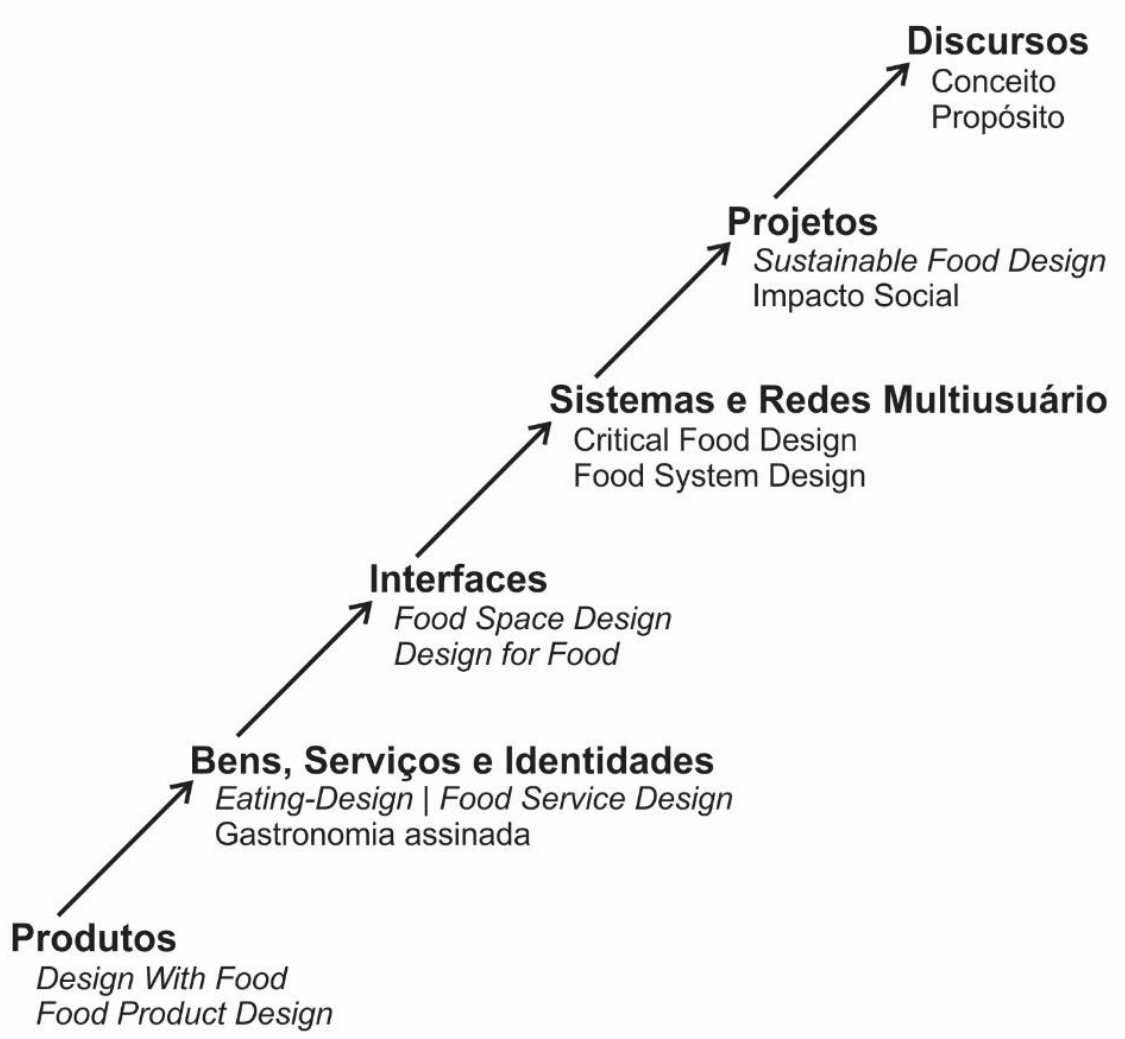

Fonte: adaptação de Krippendorf, 2006.

A partir disso, na trajetória da artificialidade aplicada ao Food Design, o produto diz respeito ao alimento produzido e suas características de conhecimento global. Bens, serviços e identidades estão relacionados às situações alimentares únicas, e as características particulares do chef, como 
trabalha os ingredientes, quais sabores imprime nos pratos, como cliente é recebido no restaurante. $\mathrm{O}$ artefato das interfaces, por sua vez, corresponde à atmosfera do ambiente de consumo, cardápio, coberta utilizada para servir, apresentação do prato; quando aplicada ao Food Design, as interfaces devem permitir a conexão do consumidor com a comida antes mesmo do consumo.

Os sistemas e redes multiusuários envolvem o sistema relacionado ao alimento: da produção do ingrediente, além dos periódicos especializados em gastronomia, críticos e premiações. Os projetos tangem a atuação do profissional no ambiente sociocultural, na busca por inovação e mudanças de comportamento, além da preocupação com a sustentabilidade. $\mathrm{O}$ discurso carrega consigo a mensagem que o chef transmite através das suas práticas e identidade.

Para um ensaio da aplicação da trajetória da artificialidade ao Food Design, buscando visualizar possíveis pontos convergência ou divergência entre as trajetórias dos chefs, proponho um quadro que faça o cruzamento entre os tipos de artefatos definidos pelo autor, com os episódios da série Chef's Table, esboçando a trajetória da artificialidade que constitui o problema de projeto e as práticas de cada profissional, conforme quadro 01.

Quadro 01: Trajetória da Artificialidade Chef's Table.

\begin{tabular}{|c|c|c|c|c|c|c|}
\hline & Produto & $\begin{array}{l}\text { Bens, Serviços e } \\
\text { Identidades }\end{array}$ & Interfaces & $\begin{array}{l}\text { Sistemas e Redes } \\
\text { Multiusuários }\end{array}$ & Projetos & Discursos \\
\hline $\begin{array}{c}01 \\
\text { Massimo } \\
\text { Bottura }\end{array}$ & $\begin{array}{l}\text { Comida } \\
\text { Italiana }\end{array}$ & $\begin{array}{l}\text { Ingredientes da } \\
\text { região. } \\
\text { Cozinha Italiana } \\
\text { Pós-moderna. }\end{array}$ & $\begin{array}{l}\text { Prato como obra de } \\
\text { arte que conta sua } \\
\text { história. } \\
\text { Ambiente familiar. }\end{array}$ & $\begin{array}{l}\text { Produtores Locais } \\
\text { Críticos e Periódicos } \\
\text { de Gastronomia } \\
\text { Estrela Michelin }\end{array}$ & $\begin{array}{l}\text { Risoto Cacio e Pepe e } \\
\text { o terremoto de } 2012 \\
\text { em Modena. }\end{array}$ & $\begin{array}{l}\text { Memórias reinterpretadas. } \\
\text { Nova geração na cozinha italiana. } \\
\text { Respeito ao ingrediente. }\end{array}$ \\
\hline $\begin{array}{l}02 \text { Dan } \\
\text { Barber }\end{array}$ & $\begin{array}{l}\text { Gastronomia } \\
\text { sazonal. }\end{array}$ & $\begin{array}{l}\text { 'Farm to table'. } \\
\text { A origem dos } \\
\text { ingredientes. }\end{array}$ & $\begin{array}{l}\text { Granja Blue Hill } \\
\text { Cardápio lista os } \\
\text { ingredientes } \\
\text { produzidos na granja. }\end{array}$ & $\begin{array}{l}\text { Críticos e Periódicos } \\
\text { de Gastronomia } \\
\text { Universidades } \\
\text { Empresas }\end{array}$ & $\begin{array}{l}\text { Granja laboratório com } \\
\text { foco na pesquisa e na } \\
\text { educação. } \\
\text { Interdisciplinaridade. }\end{array}$ & $\begin{array}{l}\text { 'Farm to table'. } \\
\text { Gastronomia holística. } \\
\text { A melhoria contínua do sistema } \\
\text { como um todo, do ingrediente à } \\
\text { mesa. }\end{array}$ \\
\hline $\begin{array}{l}03 \text { Francis } \\
\text { Mallmann }\end{array}$ & $\begin{array}{l}\text { Gastronomia } \\
\text { rústica. }\end{array}$ & $\begin{array}{l}\text { A gastronomia } \\
\text { primitiva da } \\
\text { Patagônia. }\end{array}$ & $\begin{array}{l}\text { Cozinha ao ar livre. } \\
\text { Exuberância e } \\
\text { sensualidade da } \\
\text { natureza selvagem. }\end{array}$ & $\begin{array}{l}\text { Maestranza. } \\
\text { Críticos e Periódicos } \\
\text { de Gastronomia } \\
\text { Gran Prix da } \\
\text { Alemanha }\end{array}$ & - & $\begin{array}{l}\text { O teatro da comida. } \\
\text { Reverenciar o tempo do fogo e o } \\
\text { que se cozinha. }\end{array}$ \\
\hline $\begin{array}{c}04 \text { Nicki } \\
\text { Nakayama }\end{array}$ & $\begin{array}{l}\text { Cozinha } \\
\text { japonesa. }\end{array}$ & $\begin{array}{l}\text { Cozinha japonesa } \\
\text { criativa. } \\
\text { Kaiseki } \\
\text { Um menu para cada } \\
\text { cliente. }\end{array}$ & $\begin{array}{l}\text { Prato como uma obra } \\
\text { de arte executada no } \\
\text { mínimo detalhe. } \\
\text { Atmosfera } \\
\text { minimalista. }\end{array}$ & $\begin{array}{l}\text { Críticos e Periódicos } \\
\text { de Gastronomia } \\
\text { Plataforma com } \\
\text { cadastro dos clientes } \\
\text { e suas preferências. }\end{array}$ & - & $\begin{array}{l}\text { "Minha culinária traduz para quem } \\
\text { come o que eu sou." } \\
\text { Empoderamento feminino. } \\
\text { Kaiseki: da cultura do ingrediente } \\
\text { à forma de cozimento. }\end{array}$ \\
\hline $\begin{array}{l}05 \text { Ben } \\
\text { Shewry }\end{array}$ & $\begin{array}{l}\text { Cozinha } \\
\text { Australiana }\end{array}$ & $\begin{array}{l}\text { Ingredientes } \\
\text { nativos. } \\
\text { Sequência de } \\
\text { pratos orquestrada. }\end{array}$ & $\begin{array}{l}\text { lluminação focada na } \\
\text { comida. } \\
\text { Atmosfera teatral. } \\
\text { Ambiente simples. }\end{array}$ & $\begin{array}{l}\text { Críticos e Periódicos } \\
\text { de Gastronomia } \\
\text { Premiações }\end{array}$ & $\begin{array}{l}\text { Cozinha experimental - } \\
\text { tentativa e erro. }\end{array}$ & $\begin{array}{l}\text { A apropriação de sabores ocultos } \\
\text { proporcionando experiências } \\
\text { gastronômicas emocionais. } \\
\text { Conexão com as raízes. }\end{array}$ \\
\hline $\begin{array}{c}06 \\
\text { Magnus } \\
\text { Nilsson }\end{array}$ & $\begin{array}{l}\text { Culinária } \\
\text { Nórdica }\end{array}$ & $\begin{array}{l}\text { Técnicas peculiares } \\
\text { para conservação } \\
\text { dos ingredientes no } \\
\text { período de inverno. } \\
\text { Ritmo calculado } \\
\text { para servir o cliente. }\end{array}$ & $\begin{array}{l}\text { Paisagem } \\
\text { escandinava do } \\
\text { trajeto ao prato } \\
\text { servido. } \\
\text { No meio do nada. }\end{array}$ & $\begin{array}{l}\text { Críticos e Periódicos } \\
\text { de Gastronomia } \\
\text { Premiações }\end{array}$ & - & $\begin{array}{l}\text { "O prato nunca será melhor que o } \\
\text { ingrediente". } \\
\text { "As técnicas comuns em outros } \\
\text { restaurantes não se aplicam ao } \\
\text { Faviken". }\end{array}$ \\
\hline
\end{tabular}

Fonte: os autores.

\subsection{Máximo Bottura}

Chef italiano de Modena, comanda o Osteria Francescana, reinventa a culinária italiana através de pratos tradicionais desconstruídos, que contam histórias como obras de arte, 
reinterpretando as memórias da casa da mama italiana. Sua gastronomia é identificada como a cozinha italiana pós-moderna, o que segundo ele abre portas para uma nova geração na culinária italiana. Após o terremoto de 2012, ao compartilhar com o mundo a receita 'Risoto Cacio e Pepe', impediu a falência dos produtores de parmesão de Modena.

\subsection{Dan Barber}

Dan Barber tem a Granja Blue Hill, no entorno de Nova lorque, onde produz todos os ingredientes servidos no seu restaurante situado em meio a paisagem dos campos. Dan afirma que o sabor do ingrediente é consequência da qualidade do pasto consumido pela vaca leiteira, portanto o trabalho dele é focado na melhoria contínua do sistema. Extensos projetos de pesquisa com profissionais de todas as áreas, vinculados a universidades e empresas, são desenvolvidos na Granja Blue Hill, com intuito de mudar a comunidade e o mundo. Segundo ele, é reinventando um jantar sofisticado para depois redefinir uma cultura do dia a dia.

\subsection{Francis Mallmann}

Chef argentino que explora técnicas antigas de culinária, desenvolvendo a gastronomia primitiva da Patagônia. Francis valoriza a exuberância da natureza selvagem, de onde vem os ingredientes, e onde o tempo do fogo deve ser respeitado. Como a maioria dos chefs da série, transitou por cozinhas consagradas, tradicionais na alta gastronomia, mas se encontrou na valorização da sua terra, recebendo prêmios a partir de então. O trabalho da sua equipe é orquestrado pela maestranza, onde todos que estão ao redor ajudam em todo o processo.

\subsection{Nicki Nakayama}

Comanda o N/Naka, se destaca pela criatividade que aplica na culinária japonesa Kaiseki. A filosofia Kaiseki significa trabalhar com os melhores ingredientes possíveis vindos da natureza, respeitando a sua sazonalidade, preparando-os através de diversos tipos de alimento. Nicki, serve menus personalizados aos clientes registrando os pratos que consomem, para que na próxima visita experimentem algo desconhecido.

\subsection{Ben Shewry}

Neozelandês, dono do Attica em Melbourne, desenvolve a culinária australiana a partir de ingredientes nativos. Nas noites de terça-feira, serve pratos elaborados na sua cozinha experimental com ingredientes nunca utilizados antes, e de forma passional recebe a resposta positiva ou negativa do consumidor. Ao revelar esses sabores ocultos, o grande objetivo de Ben é provocar experiências gastronômicas emocionais intensas.

\subsection{Magnus Nilson}

Atua no Fäviken, em Järpen na Suécia, um restaurante de 12 lugares escondido entre florestas e fiordes nórdicos, onde nada cresce durante os seis meses de inverno, utilizando ingredientes regionais, trabalhando arduamente no aprimoramento de técnicas pitorescas de conservação e preparo da comida, imprimindo sua criatividade peculiar. Seus pratos simulam a paisagem local e o ritmo do serviço é milimetricamente calculado, afim de deixar o consumidor confortável e surpreso durante sua estada no restaurante.

A planificação das consoantes através do quadro permitiu a percepção dos pontos de convergência e divergência. Não obstante, as "divergências" estejam diretamente relacionadas às identidades dos chefs, e as rupturas geradas pelas suas cozinhas. Muito embora, o entendimento 
feito a partir da trajetória de Krippendorf (2006) é que, o fato de apresentarem identidades diversas não se configura de fato como uma divergência, visto que o desenvolvimento de identidades particulares é algo evidente e esperado.

Partimos do princípio óbvio, todos os profissionais presentes na série são chefs da alta gastronomia, que proporcionam experiências particularmente extraordinárias aos frequentadores dos seus restaurantes. Contudo, enquanto a maioria atua em grandes centros ou próximos deles, Francis e Magnus operam suas cozinhas em locais pitorescos, em cantos opostos do mundo, na Patagônia e em um pequeno vilarejo da Suécia, ambos se apropriam da natureza e da sua sazonalidade com maestria. Um dos pontos em comum entre todos os chefs, diz respeito aos ingredientes. $\mathrm{Na}$ busca pelo melhor sabor, todos os profissionais valorizam os ingredientes regionais, nativos, produzidos de forma orgânica-sustentável, seguindo na contramão da indústria alimentícia que atua na produção em massa de alimentos superprocessados (MERONI, 2006).

Além disso, os seis chefs são pesquisadores e incorporam a inovação em suas cozinhas, seja aprimorando técnicas primitivas ao mesmo tempo que criam as suas próprias. Porém, apenas Massimo, Dan e Ben trabalham em projetos com participação da comunidade local ou organizações, conforme citado anteriormente, Massimo Bottura se apropria da sua cozinha e cria uma receita capaz de salvar uma rede de produtores locais, Dan e Ben em suas cozinhas laboratoriais. As redes de multiusuários estão relacionadas ao reconhecimento pela crítica especializada, e às plataformas de relacionamento com os produtores, clientes, equipe, organizações; e ao Netflix que permitiu que esses chefs ficassem conhecidos ao redor do mundo, por pessoas que não necessariamente sejam especialistas em gastronomia.

Por fim, discurso de cada chef é resultado de toda a sua trajetória da artificialidade. Afinal, sem sua cozinha, sem sua identidade, sem as interfaces de contato com o consumidor e, além disso, sem a história do local e da comunidade onde os chefs e seus restaurantes se inserem, bem como o percurso que os levou até lá, o discurso não faria sentido.

\section{Conclusões}

A medida que o designer desenvolve um olhar sensível às mudanças de comportamento da sociedade e do meio ambiente, torna-se incompreensível conceber o design de produto sem considerar o impacto que vai causar no usuário e na sociedade, ou ignorar os outros níveis de artificialidade que se incorporam ao significado do produto. Ao mesmo tempo, é acentuada a conexão entre os seis tipos de artefatos, e a demanda imperativa de processos projetuais sistemáticos e integrados (MANZINI, 2016). Isso tornou o exercício de descrever as trajetórias dos profissionais do Chef's Table em um quadro, separando os tipos de artefatos, uma tarefa difícil. Visto que, o mesmo prato definido como produto, é um bem de mercado ao ter a assinatura do chef atribuída, atingindo consumidores interessados em vivenciar a experiência anunciada, e a assinatura é a impressão de uma identidade que está diretamente relacionada com o discurso desse profissional. Ou seja, embora a alternativa de planificar as seis trajetórias organizando-as por tipos de artefato, tenha sido eficiente para perceber os pontos de convergência na cultura do Food Design, os tipos de artefatos são indissociáveis.

Concluindo, este trabalho foi um ensaio da aplicação da trajetória da artificialidade ao Food Design, estudando as práticas de profissionais da alta gastronomia retratados em uma série online, 
permitiu olhar para a conexão entre os artefatos e a importância de serem considerados desde o início como parte do problema de projeto. Considerando a abrangência do campo do Food Design, outras aplicações podem ser estudadas, como a trajetória das cadeias de restaurantes.

\section{Referências}

CHEF'S TABLE. Estados Unidos: Netflix, 2015. 1a temporada. Disponível em: https://www.netflix.com/br/title/80007945.

KRIPPENDORFF, K. The semantic turn. A new foundation for design. Boca-Raton: Taylor \& Francis, 2006. Seções 1.2 (p.5-13).

MANZINI, E. Design Cultures and Dialogic Design. Design Issues: Volume 32, Number 1 Winter, 2016.

MERONI, A. Strategic Design: where are we now? Reflection around the foundations of a recent discipline. In: Strategic Design Research Journal, v1, n.1, Dec 1, 2008. p.31-38.

MERONI, A. Strategic Design for the Food Sector: food-system innovation. In: 1o International Product and Service Design Symposium and Exhibition on Agricultural Industries: Olive Oil, Wine and Design Proceedings. Izmir: Izmir University of Economics, Department of Industrial Design, 2006. p.212-223.

ZAMPOLLO, F. What is Food Design? The complete overview of all Food Design sub-disciplines and how they merge. 2016. Disponível em: https://www.researchgate.net/publication/310706545. 